CHAPTER 15

\title{
Mutual Accountability in African Agricultural Transformation
}

John M. Ulimwengu, Greenwell Matchaya, Tsitsi Makombe, and James Oehmke ${ }^{1}$

1 The views presented in this chapter are those of the authors and do not necessarily reflect the views of the US Agency for International Development. 
M utual accountability is rooted in the observation that development is a multistakeholder phenomenon and that stakeholders must therefore hold themselves and others accountable for their commitments to the development process for that process to succeed. Jointly, stakeholders must be accountable for ensuring that the set of commitments suffices to achieve common development goals. The potential of mutual accountability to align multistakeholder commitments around common development goals and ensure efficient execution of these commitments makes it one of the most exciting development innovations of the decade. In African countries plagued with inefficient markets and weak contracting mechanisms, mutual accountability provides an additional tool to align resources in multistakeholder situations, with considerable potential to mobilize those resources and improve the efficiency of their use-perhaps the most critical concerns for sustainable development. However, a lack of mutual trust among business, civil society, and government; data and evidence constraints; and limited capacity for multistakeholder dialogue may make it exceedingly difficult for mutual accountability to live up to its full potential.

Simply put, mutual accountability is a process by which two or more partners agree to be held responsible for commitments that they have voluntarily made to each other (OECD 2009). The "mutual" refers to that which is common and shared among the partners, which includes having a shared agenda and vision for achieving desired development outcomes and having jointly agreed performance indicators based on agreed performance criteria. A shared agenda is central to establishing and sustaining buy-in, unity, and commitment among stakeholders or participating members. It is essential for shared goals and commitments to be SMART_-specific, measurable, achievable, relevant, and time-bound. Effective mutual accountability requires common performance indicators based on mutually agreed performance criteria that can be used to monitor and adjust progress on the commitments and goals. The "accountability" part of mutual accountability consists of two important dimensions-answerability and enforceability (SADEV 2012; Vance, Lowry, and Eggett 2013). Answerability implies that one must justify to others one's actions or decisions; it is "a responsibility to answer for particular performance expectations to specific stakeholders" (Brown and Jagadananda 2007,9). And enforceability involves ensuring that an actor sticks to his or her commitments; this part of accountability renders judgment or imposes sanctions on the actions (or lack thereof) of participating persons (Brown and Jagadananda 2007).

Mutual accountability is furthermore rooted in the concept of managing for development results (MfDR), a management approach that uses performance information at all stages of the development process to make better and more effective decisions and to steer development efforts toward clearly defined goals. The MfDR approach covers five areas: (1) setting desired results and agreeing on targets and strategies, (2) allocating available resources to activities that will contribute to the achievement of results, (3) monitoring and evaluating progress to assess whether results are being achieved, (4) reporting on performance, and (5) learning from the experience and providing feedback to improve decision making (OECD 2005). Mutual accountability provides a platform or a mechanism to operationalize the five core areas of MfDR and to ensure effective delivery and tracking of shared commitments as well as increased accountability and performance, and ultimately the achievement of desired results in the improvement of livelihoods

Mutual accountability has been a core principle of the New Partnership for Africa's Development (NEPAD) since its adoption by the African Union (AU) in 2002, and of the Comprehensive Africa Agriculture Development Programme (CAADP) since its launch in 2003. In line with NEPAD principles of African collective ownership and leadership around a shared vision and of good governance and accountability, CAADP has emphasized the need for improved agriculture sector governance through promoting benchmarking, dialogue, review, and mutual learning and accountability in the agriculture sector (NEPAD Secretariat 2005). Since 2014, the African Union Commission (AUC) and the African Union Development Agency-NEPAD (AUDA-NEPAD) have led efforts to establish and strengthen agriculture joint sector reviews (JSRs) - a key instrument for operationalizing mutual accountability by mutually assessing performance and progress in the agriculture sector and allowing state actors and nonstate actors (NSAs) to hold each other accountable on their commitments and outcomes. In 2014, African heads of state and government reaffirmed their commitment to mutual accountability and the entire CAADP agenda by adopting the Malabo Declaration on Accelerated Agricultural Growth and Transformation for Shared Prosperity and Improved Livelihoods (AU 2014). In a strong show of their commitment, African leaders pledged to hold a continental 
agricultural biennial review (BR) to assess progress on all seven Malabo commitment areas.

This chapter aims to deepen our understanding of both the conceptual framework of mutual accountability and its best practices in the context of agricultural transformation in Africa. We do so in three ways: documenting the need for and growth of mutual accountability mechanisms over time, discussing how mutual accountability processes contribute to agricultural transformation, and examining the effectiveness of the mutual accountability processes of choiceJSRs and the African agricultural BR. In the next section, we provide a brief review of the origins and theory of mutual accountability as well as its application in African agriculture. Following that, we discuss how mutual accountability is being operationalized through JSRs and the Malabo BR, and the effectiveness of the two processes. The section after empirically assesses the contribution of mutual accountability to agricultural transformation in Africa. The final section provides concluding remarks for driving agricultural transformation through mutual accountability processes.

\section{Mutual Accountability and Agricultural Transformation}

\section{The Evolution and Theory of Mutual Accountability}

The concept of mutual accountability originated in the business management literature. Katzenbach and Smith (1993) argued that mutual accountability arises naturally in well-functioning corporate teams: "teams enjoying a strong common purpose and approach inevitably hold themselves responsible, both as individuals and as a team, for the team's performance" (116). Buchanan-Smith and Collinson (2002) used the concept to describe joint commitments by donors and multilateral agencies with respect to humanitarian crises but did not articulate mutual accountability as a paradigm for improved aid effectiveness.

In 2005, the Paris Declaration on Aid Effectiveness articulated the concept of donors and national governments as partners, including the concept and application of mutual accountability, which was reaffirmed in the 2008 Accra Agenda for Action and the 2011 Busan Partnership Agreement. The immediate need for mutual accountability came from divergent priorities among government and donors. Despite agreement on the overarching framework of the Millennium Development Goals (MDGs), donor funding often came with a narrower set of objectives that did not fully match developing-country priorities. Developing countries wanted donors to provide direct government-to-government (G2G) financial support. Donors perceived public financial accounting as not transparent and voiced concerns over possible corruption and diversion of public resources. In the Paris Declaration, African governments committed to more transparent financial accounting processes and donors committed to considering G2G support or at least harmonizing off-budget support with country priorities.

The key mutual accountability characteristics of responsibility and voluntary commitment remain important today, often implemented through inclusive, evidence-based dialogue processes leading to commitments based on shared objectives (Oehmke 2017; Benin et al. 2018). A limiting feature of the Paris Declaration was that only donor and partner countries made commitments-that is, the declaration contains only government commitments. Even the recognition of the need for broad dialogue among development stakeholders was phrased in terms of government commitment to support better dialogue-there were no civil society or private sector commitments to go beyond dialogue and become part of the solution, or even to participate in dialogue at all. The Paris Declaration led to selection of the JSR as the implementing tool of choice for mutual accountability. Although the JSR began as a review of financial commitments between donors and a national government, countries have quickly learned the potential of the JSR to serve as an inclusive, evidence-based policy dialogue process, particularly in agriculture.

As stated earlier, mutual accountability has been a core principle of CAADP since its launch in 2003 but has grown in importance as the demand for evidence on progress to achieve agreed-on commitments has increased. In the 2003 Maputo Declaration, which launched CAADP, African leaders called for the active participation of civil society organizations (CSOs), smallholder farmers, the private sector, and women and youth associations in all aspects of agricultural and food production (AU 2003). An early and visible initiative is NEPAD's African Peer Review Mechanism, established in 2003, whereby AU member states voluntarily accede to a peer review process that assesses their adoption of political, economic, and corporate governance policies and practices in pursuit of political stability, economic growth, and sustainable development (APRM 2020). Both NEPAD and CAADP have promoted key principles of good governance and accountability, inclusive participation, dialogue, benchmarking, peer review, and mutual learning (NEPAD 2010). CAADP has also promoted partnerships 
and alliances that facilitate the alignment of development efforts by governments and development partners, improve incentives for long-term investments by the private sector, and increase inclusive and active participation of NSAs such as farmers' organizations in agricultural policymaking (NEPAD Secretariat 2005; NEPAD 2010).

In 2011, through a consultative process, AUC and AUDA-NEPAD developed the CAADP Mutual Accountability Framework to incentivize CAADP partners to effectively deliver on their commitments by tracking the commitments, increasing accountability, and rewarding performance (AUC and NPCA 2011). The framework document noted the existence of review mechanisms such as agriculture JSRs in a few countries and called for their strengthening as well as the establishment of accountability platforms where they do not exist. Thus, since 2014, AUC and AUDA-NEPAD, and their technical partners such as the Regional Strategic Analysis and Knowledge Support System (ReSAKSS), have led efforts to establish and strengthen JSRs. An overarching commitment of the 2014 Malabo Declaration is the pledge by African heads of state and government to hold themselves accountable over actions and results associated with provisions of the declaration by conducting a continent-level BR to monitor and report on progress. Essentially, the BR elevates attention to country JSR or equivalent processes with comparable data and evidence across countries and regions. To date, two BRs have taken place, in January 2018 and February 2020, during the AU summits of heads of state and government.

In both the 2003 Maputo Declaration and the 2014 Malabo Declaration, African leaders committed to increase financial support for agriculture and make spending more effective through CAADP. Donors and governments quickly realized that they did not have the ability to fully fund agricultural development either individually or jointly: smallholders invest three to seven times more than donors, governments, and the for-profit private sector combined (Lowder, Skoet, and Raney 2016; FAO 2012). Thus, the mutual accountability process that has emerged under the CAADP agenda goes beyond the focus on donors and country governments, and in line with the CAADP principle of inclusiveness, opens up the process and dialogue space to all stakeholder groups including NSAs such as farmers' organizations, the private sector, CSOs, youth associations, and nongovernmental organizations (NGOs). Moreover, it represents a move from vertical accountability mechanisms-which characterized past aid modality relationships between donors and country governments-to horizontal accountability-which tries to deal with inherent power imbalances between donors and governments by emphasizing mutual respect, trust, reciprocal commitments, and mutual responsibility (Brown and Jagadananda 2007).

Although mutual accountability processes can operate at levels from grassroots to continental (Oehmke 2017; Oehmke et al. 2018; Oehmke, Kagniniwa, and Franklin 2018; Franklin and Oehmke 2019), the emphasis in this chapter is on agricultural JSRs and the BR. Overall, successful agricultural mutual accountability processes have the following four distinct characteristics (Oehmke 2017):

1. A common vision of development that includes overlapping stakeholder interests and is publicly articulated, for instance in a National Agriculture Investment Plan (NAIP) or on a smaller scale in a local resilience plan

2. Voluntary and transparent commitment to actions in support of the common vision

3. A means for individuals to hold themselves and others accountable for responsible execution of these commitments

4. Joint accountability to ensure that the portfolio of commitments is sufficient to progress toward development goals

Other key characteristics or principles that have emerged under the CAADP agenda as critical for the success of mutual accountability processes include (1) country ownership and leadership to ensure the success and sustainability of the processes; (2) inclusive participation that ensures all stakeholders actively and fully participate in the process and have access to timely, transparent, and relevant information; and (3) evidence-based decision making, whereby reliable data, performance monitoring information, and evidence-based analysis are made accessible to all stakeholders and used to guide policy decisions (Benin et al. 2018). The use of credible data and analysis helps to build trust among stakeholders that contribute to the process. The novelty and potential of mutual accountability arise from the nature of commitment and enforcement in mutual accountability processes and the ability to strengthen social institutions for accountability. For example, the MDGs exemplify both a common vision and voluntary commitment-but the MDGs were not achieved, in large part because of nonspecific commitments and ineffective enforcement processes. 
Enforcement in mutual accountability is accomplished primarily through social institutions that offer "answerability," although some legal changes are often required as well. Mutual accountability is in part a collaborative accountability or social accountability (Fox 2015) based on shared interests and commitments to achieve common goals, with limited specific political, legal, or economic sanctions in place. Therefore its enforceability relies primarily on "soft" sanctions: social or reputational forces such as peer pressure or peer review (Brown and Jagadananda 2007; Droop, Isenman, and Mlalazi 2008). In circumstances where legal or economic penalties are effective, it is likely that market mechanisms, contracting, grades and standards, or other traditional resource commitment and allocation mechanisms may be relatively efficient and are the mechanisms of choice. On the other hand, in circumstances where these traditional sanctions are difficult or impossible to enforce impartially, a mutual accountability process that relies on social, relational, and reputational forces is likely to be a useful tool in advancing multistakeholder development goals.

Mutual accountability under the CAADP agenda is a voluntary cooperative action based on shared interests and commitments to achieve common goals. Its enforceability relies both on social or reputational forces such as peer pressure or peer review, and on the ambition of reaching the shared vision that provides benefit to stakeholders. The BR process is already showing that reputational risks can be effective in getting $\mathrm{AU}$ member states to participate in reporting progress toward Malabo Declaration commitments. A total of 49 out of $55 \mathrm{AU}$ member states participated in the 2019 BR, compared with 47 out of 55 in 2017 (AUC 2020), and the best-performing countries are honored among their peers, a practice that can help incentivize other countries to take measures to improve their own agricultural transformation outcomes.

\section{Mutual Accountability and Agricultural Transformation}

Through the 2014 Malabo Declaration, African leaders pledged, between 2015 and 2025, to accelerate agricultural transformation, a process that involves the modernization of the agriculture sector from subsistence farming to a modern commercialized agriculture that has strong linkages to other sectors of the economy. In essence, agricultural transformation is characterized by (1) a relative decline of basic subsistence agriculture, (2) a rising importance of agribusiness and increased value added for agro-industries and agricultural trade and services, and (3) an increasing share of high-value agricultural products in international trade (Divanbeigi, Paustian, and Loayza 2016; Barrett et al. 2017).

Agricultural transformation is very complementary to the broader process of structural transformation, which involves the reallocation of economic activity across the agriculture, manufacturing, and services sectors. Structural transformation is often characterized by a falling share of agriculture in economic output and employment, a rising share of urban economic activity in industry and services, migration of rural workers to urban areas, and a demographic transition from high rates of births and deaths to low rates of births and deaths (Timmer and Akkus 2008; Breisinger and Diao 2008). The agriculture sector plays a key role in structural transformation, especially as a source of labor for the modern industrial sector and of food supplies for the laborers (Lewis 1954; Johnston and Mellor 1961), and as a source of fiscal revenue for financing infrastructure, health, and education (Badiane and McMillian 2015). Furthermore, evidence from Asia has shown that poverty reduction is fastest when agricultural transformation complements the structural transformation process (Timmer and Akkus 2008; World Bank 2007).

The development hypothesis undergirding the recommitment to CAADP is that application of the CAADP principles and values, including good governance, good policies, and effective mutual accountability processes, will lead to better development outcomes (Figure 15.1) (Benin, Ulimwengu, and Tefera 2018). Adherence to CAADP principles and values, including effective mutual accountability processes, is expected to improve the policymaking process and to safeguard the design and implementation of good policies, effects that in turn are expected to lead to desirable policy outcomes. Expected outcomes include increases in the amount and quality of public and private investments, improved access to technologies and markets, reductions in postharvest losses, greater employment for women and youth, and stronger systemic capacity for policy formulation and implementation. Ultimately, countries and the continent are expected to realize accelerated, inclusive agricultural transformation and the associated Malabo goals: increased trade; reduced poverty, hunger, and undernutrition; enhanced food security; and better resilience. Thus, effective mutual accountability processes contribute to agricultural transformation through improvements in agriculture sector governance: policy efficiency, improved strategies, and policy and institutional reforms. 


\section{FIGURE 15.1—MALABO DECLARATION IMPACT PATHWAY}

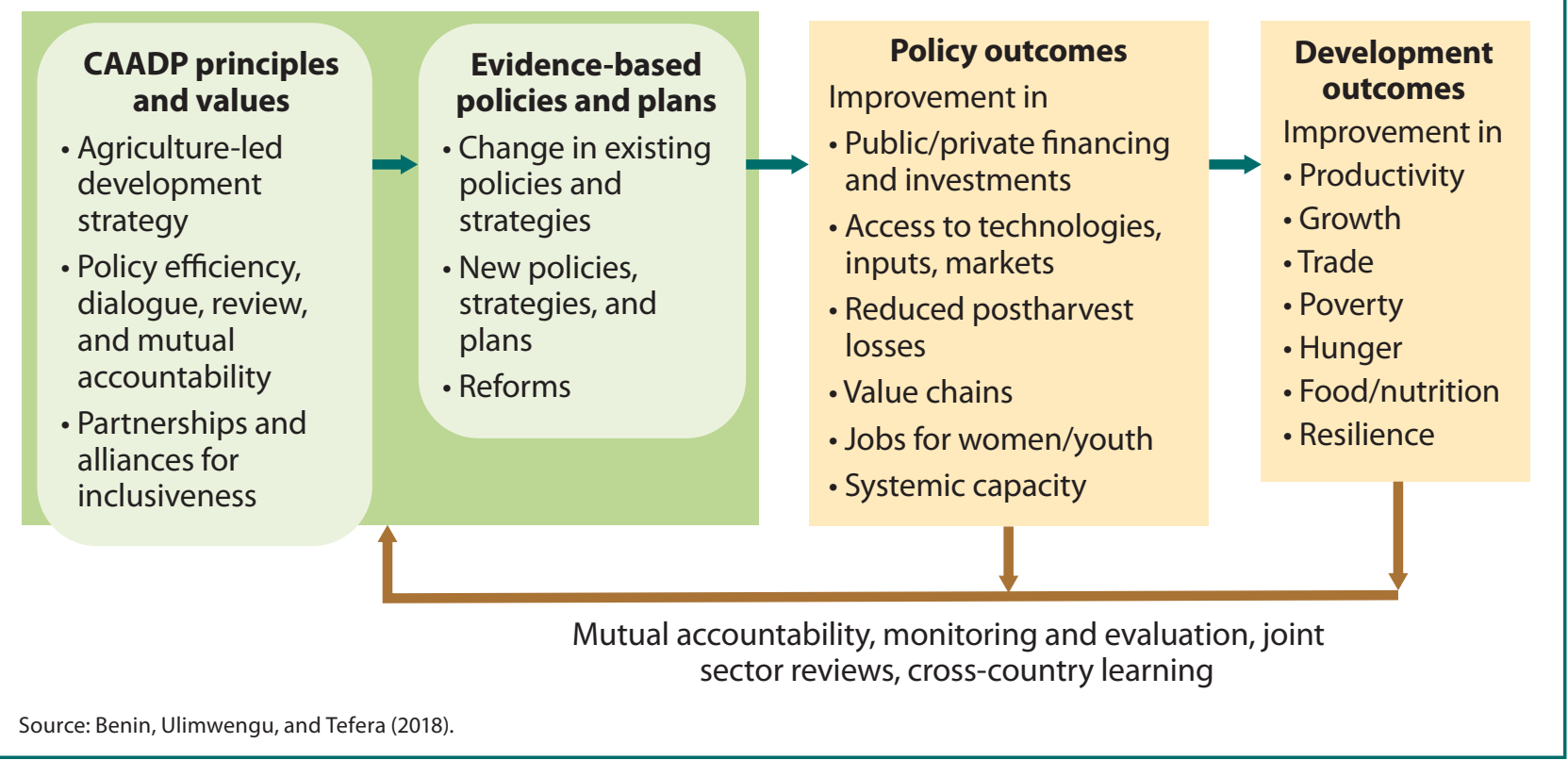

Although the various theoretical and empirical studies that have looked into the determinants of agricultural transformation or structural transformation have not directly considered mutual accountability and its potential role in supporting agricultural transformation, these studies have emphasized the important role played by good agriculture sector governance, and institutional and policy reforms. For example, Jayne, Chamberlin, and Benfica (2018) highlighted good governance and the policy reforms of the 1980s and 1990s as key drivers of Africa's transformation. Dabla-Norris and others (2013) found that policy and institutional variables such as product market reforms, openness to trade, and human and physical capital are important determinants of structural transformation. McMillan and Rodrik (2011) showed that structural change in Asia has been growth-enhancing due to policy and institutional factors such as having flexible labor markets and competitive real exchange rates to promote trade. Mensah and colleagues (2016) used a cross-country study of African countries to highlight the strong role played by policy and institutional reforms (for example, education, trade openness, and financial reforms), as well as governance and fiscal reforms, in driving structural transformation. Anderson, Rausser, and Swinnen (2013) documented the political economy difficulties in advancing policy change, which suggest that adopting systemic approaches such as mutual accountability may be more effective than taking on policy changes piecemeal.

\section{Operationalizing Mutual Accountability}

This section discusses the processes that are used to operationalize the concept of mutual accountability in the agriculture sector, as introduced in the foregoing section. Our focus is on the agriculture JSR and the CAADP BR, processes that, as described later, are closely related to one another and implemented for the same purposes.

\section{Agriculture Joint Sector Reviews}

The basis of an agriculture JSR as a tool for operationalizing mutual accountability in the agriculture sector is the country's NAIP, which sets out jointly agreed objectives and goals for the agriculture sector as well as details about monitoring progress in the pursuit of the objectives. NAIP reviews, such as mid-term program reviews, JSRs, and sector performance assessments, are important for successful NAIP implementation (AUC and NPCA 2016). Participants in agriculture sector reviews include the ministry of agriculture, other line ministries that perform functions with a bearing on agriculture (such as finance, trade, public works, and health), development partners, civil society, the private sector, and farmer organizations.

\section{The Process and Conduct of a Typical Joint Sector Review}

JSRs provide a platform to assess the performance and results of the agriculture sector, and in turn, assist governments in setting sector policy and priorities. Specifically, they aim to assess how well state and nonstate stakeholders have 
implemented pledges and commitments stipulated in the CAADP compacts, NAIPs, and related cooperation agreements in the sector (ReSAKSS 2013). By allowing a broad spectrum of stakeholders to get insights into and influence overall policies and priorities of the sector, JSRs serve as a management and policy support tool for inclusive stakeholder planning, programming, budget preparation and execution, monitoring and evaluation (M\&E), and overall development of the sector (ReSAKSS 2013; CAADP MA-M\&E JAG 2012). The JSRs also facilitate information sharing and consensus building among different stakeholders, and encourage evidence-based decision making (Benin et al. 2018). For a JSR to be successful and robust, it needs to conform to certain procedural and substantive elements. The JSR process involves setting up a JSR steering committee chaired by the ministry of agriculture, followed by establishing a JSR secretariat, developing JSR terms of reference, mobilizing resources for the review, and constituting the review team. These activities are followed by conducting the review studies in line with the focus of the JSR that year, and compiling reports based on the studies. After a given report is cleared by senior managers, it is shared with all key sector players for review in preparation for validation (Benin et al. 2018). During the stakeholder dialogue, implementation and follow-up plans for the recommendations from the JSR are also drawn up (see Bahiigwa, Matchaya, and Benin 2013). The JSR report validation is the culmination of stakeholder participation and transparency in the process of the review. At this meeting, the report is presented, discussed, and critiqued, with the view of improving it and ensuring it is viewed as credible by all key sectoral players. The results from the validation are used to improve the report before it is finally shared with a wider variety of stakeholders, including the AUC (see Benin et al. 2018). The sector then drafts sectoral action plans.

The substance of the JSR derives from the mutually agreed milestones and targets laid out in the NAIP (ReSAKSS 2013). The substance is usually organized around five main areas: (1) development results, such as income growth, poverty and hunger reduction, food and nutrition security, and so on; (2) an overall agriculture sector growth target, with specific subsector and commodity targets; (3) required financial and nonfinancial resources; (4) policies, programs, institutions, and implementation processes; and (5) linkages (including pathways to achieve the development results), enabling environment, and assumptions (ReSAKSS 2013; CAADP MA-M\&E JAG 2012; Benin et al. 2018). In some cases, deeper analysis may be conducted on a special or time-sensitive topic. A typical JSR can hence have its substance or topic focus on any one or various combinations of these five areas. For the chosen focus area, the JSR process will then identify (1) the main questions to be answered, (2) the methodologies and data needed for answering these questions, and (3) the outputs or reports to be generated (ReSAKSS 2013). Once the review terms are agreed upon and elaborated, the review of the sector then involves collecting, analyzing, and organizing relevant data from the sector in order to answer the key questions. This stage constitutes looking back to reexamine the actions taken by the stakeholders in the sector and evaluating them against the previously set joint targets in order to gauge the level of progress, or lack thereof, made.

\section{Effectiveness of the Joint Sector Review as a Mutual Accountability Tool ${ }^{2}$}

Since 2014, ReSAKSS, in partnership with the AUC and AUDA-NEPAD, has launched assessments of JSR efforts in 21 countries and two regional economic communities (RECs). ${ }^{3}$ The assessments evaluate the institutional and policy landscape as well as the quality of current agricultural review processes, and then develop action plans for improving or establishing best-practice JSRs that are regular, comprehensive, and inclusive.

These assessments have shown that many sectoral review processes had both similarities with and differences from the ideal JSR. Beyond the JSR assessments conducted by the AUC and ReSAKSS in 21 countries, some countries were shown to have only "JSR-like" processes that do not exhibit all the elements of a best-practice JSR but generally take place annually and are used to review agriculture sector performance (Nhemachena, Matchaya, and Nhlengethwa 2017). Out of 32 countries that conducted an agriculture JSR or JSR-like review in the past five years, 11 were in western Africa, 11 were in southern Africa, and 10 were in eastern Africa. The majority of the countries that have not conducted JSR or JSR-like processes are in central and northern Africa. At the regional level,

2 This section is based on the experience of ReSAKSS in supporting JSR processes at the country and regional levels.

3 The countries are Angola, Benin, Burkina Faso, Côte d'Ivoire, Democratic Republic of the Congo, Eswatini, Ethiopia, Ghana, Kenya, Malawi, Mali, Mauritius, Mozambique, Niger, Senegal, Seychelles, Tanzania, Togo, Uganda, Zambia, and Zimbabwe. RECs are the East African Community and the Economic Community of West African States. 
the Economic Community of West African States has to date held one regional JSR and is gearing up for a second one in 2020. The East African Community is expected to conduct its first regional JSR in 2020 following its JSR assessment in 2019.

JSR assessments or JSR-like processes have not been reported to have been conducted in a total of 23 African countries. ${ }^{4}$ Future assessments in these countries could help establish whether or not the countries have JSR or JSR-like reviews in place, and could develop action plans for establishing or strengthening such reviews.

Findings of the assessments also show that existing sectoral review practices are narrow in scope, not fully inclusive, not predicated on consensus, and not wholly country-owned (Nhemachena, Matchaya, and Nhlengethwa 2017). Further, the findings from the initial JSR assessments, when compared with the expectations set out in the JSR guidelines (ReSAKSS 2013), showed that the review processes did not include a review of agricultural policies and were not followed up with policy actions as recommended by the JSR review guidelines (Nhemachena, Matchaya, and Nhlengethwa 2017). For example, both the Ghana (Ghana, MoFA 2014) and Malawi (Malawi, MoAFS 2014) JSR assessments in 2014 showed that private sector involvement was lacking and action recommendations from reviews were often never followed up, even though this is a cardinal recommendation of the JSR guidelines (ReSAKSS 2013). In all the JSR assessment countries, there was a willingness by country stakeholders to improve the process following the assessments.

Outcomes of the assessments have been used to strengthen agriculture JSR processes where they existed prior to the assessments (for example, in Eswatini, Ghana, Malawi, Mozambique, and Zambia) and establish new JSRs where they did not (for example, in Burkina Faso and Senegal); further, countries have expanded the scope of their JSRs, compared with past reviews. ${ }^{5}$ Country stakeholders expressed their willingness to draw up action plans based on the assessments in order to improve agriculture sector performance (Nhemachena, Matchaya, and Nhlengethwa 2017). In addition, JSRs have raised accountability standards, enhanced stakeholder engagement, and increased active participation by NSAs in JSR meetings in Eswatini, Malawi, Zambia, and Mozambique (Benin et al. 2018). JSR assessments have led to discussions about targeting public projects away from areas with a huge presence of NGOs performing similar tasks, implying that wasteful duplication of effort may be on the decline (Benin et al. 2018). JSR assessments in the countries have led to an express inclusion of NSAs in JSR meetings, although their participation still requires strengthening (Benin et al. 2018)

\section{The CAADP/Malabo Biennial Review}

The CAADP BRs are much like continental JSRs, but they differ primarily in that the Malabo Declaration (1) elevates attention to a broad set of goals, including multisectoral goals heavily influenced by agriculture and food systems, such as nutritional outcomes, trade, and employment, among others; and (2) intentionally strives for cross-country comparability in indicators, measurement, and milestones. The $\mathrm{BR}$ process contributes to the overarching principle of mutual accountability enshrined in the CAADP process, alongside JSRs, midterm reviews, and other NAIP assessments. The immediate products of the BR are the continental BR report and the African Agriculture Transformation Scorecard (AATS), which present the overall summary of a country's performance against the milestones required to be on track to achieve the Malabo targets by 2025 . Thus far, BRs have taken place in 2017 and 2019, with the presentation of BR reports and AATSs during AU summits held in January 2018 and February 2020.

Typically, the BR process begins with (1) definition and refinement of BR indicators, templates, guidelines, and methodologies; (2) training of AU member states on the BR refinements; and (3) BR data collection, analysis, reporting, and validation at the country level. The process at the country level is expected to involve all key stakeholders and utilize any existing JSR or JSR-like process, from its launch to the holding of a multistakeholder workshop to review and validate the data before they are submitted to the respective RECs and the AUC using the eBR. ${ }^{6}$ RECs provide quality control by reviewing data and providing feedback to

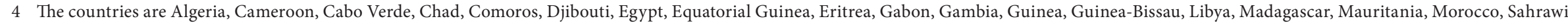
Arab Democratic Republic, Sao Tome and Principe, Somalia, South Africa, South Sudan, and Tunisia.

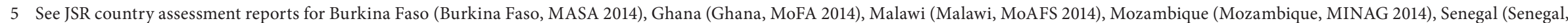
MoARE 2014), and Uganda (Uganda, MAAIF 2012).

6 The eBR is a web-based tool for easing BR data entry, access, and management, developed by ReSAKSS at the request of the AUC.
} 
countries before generating regional summaries and handing over the data to the AUC. In turn, the AUC and its technical partners generate country agricultural transformation scores and draft the continental BR report and AATSs. The BR report and AATSs are reviewed and endorsed by the AU's Specialized Technical Committee on Agriculture, Rural Development, Water and Environment before they are submitted to AU heads of state and government for presentation and review at the AU summit.

\section{Is the BR Effective as a Process?}

The BR can be considered to be effective as a process if it elevates attention to and suitably prioritizes those areas that countries need to focus on to achieve the Malabo targets, and if countries respond positively to this prioritization. Following are six examples of positive country responses.

Malawi makes data and policy improvements. The 2017 BR pointed out the need for improved data coverage and quality in several countries including Malawi. Malawiss Ministry of Agriculture and Food Security led the development of data clusters around the seven Malabo commitments. The clusters brought together leading country experts on the different commitment areas to spearhead the data collection and reporting effort. As a result, Malawi completed more data indicators, parameters, and sources in the second BR than in the first (Benin et al. 2020). At the policy level, the BR process has led to increased policy dialogue between the public and private sectors, which has in turn generated a government review of the country's fertilizer policy, fertilizer bill, seed bill, and agricultural extension and advisory strategy in order to improve access to agricultural inputs and advisory services, and ultimately increase agricultural productivity (Malawi, MoAFS 2019, 6).

Lesotho pledges to increase budget allocation for agriculture. In response to the slow increase in budget allocation to its agriculture sector, underscored by the 2019 BR, the Lesotho government pledged to increase the operational budget to the Ministry of Agriculture and Food Security by 34 percent for fiscal year 2020/2021. ${ }^{7}$

Mozambique government recommits to allocating 10 percent of budget to agriculture and institutes policy changes. In Mozambique, the BR process has helped to sensitize civil society and other stakeholders to the low levels of public agricultural spending-averaging 4.8 percent of total public spending since 2011 (Mozambique, MINAG 2020). As a result of stakeholder engagement in dialogue, the government has recommitted to allocating 10 percent of total spending to the agriculture sector annually over the next five years ${ }^{8}$ (Mozambique, MINAG 2019).

In the policy arena, the Ministry of Agriculture and Rural Development has responded to BR results by establishing a climate change unit to advise the ministry on building resilience and mobilizing resources for resilience. In response to the call to improve $\mathrm{BR}$ data, the ministry has incorporated BR indicators related to finance, climate change, and postharvest losses into its agriculture survey, and has secured funds to set up a sectorwide M\&E system in March 2020 (Mozambique, MINAG 2019, 59).

Côte d'Ivoire makes programmatic changes to increase agricultural productivity. In Cote d'Ivoire, the first BR results led to inclusion of the Ministry of Environment in NAIP processes to ensure that resilience and climate variability are discussed with a broad group of experts (Côte d'Ivoire, Ministry of Agriculture 2019). The BR also led to the adoption of an investment code in 2018 that provides tax incentives for all private investments in the agriculture sector. The BR has resulted in the launch of new projects aimed at promoting farmers' access to credit services and the creation of a rural land agency to facilitate access to land by smallholder farmers. In addition, the Millennium Challenge Corporation has provided funding to track the BR indicator on access to land (Côte d'Ivoire, Ministry of Agriculture 2019).

Niger promotes private agricultural investment. Because BR results have shown Niger to be short of the target in its investment finance in agriculture, the country (1) adopted a decree in September 2018 that created the Nigerian Agency for the Promotion of Private Investments and Strategic Projects, and (2) passed an inclusive public-private partnership law in June 2018 to govern the formation and operation of public-private partnerships (Niger, Ministry of Agriculture 2019).

\footnotetext{
Information collected by ReSAKSS from Ministry of Agriculture and Food Security in Lesotho in February 2020

8 Information collected by ReSAKSS from Ministry of Agriculture in Mozambique in February 2020.
} 
Togo makes policy and data improvements. The BR motivated the Ministry of Agriculture to introduce several new projects ${ }^{9}$ aimed at improving nutrition and promoting organic farming across the country (Togo, Ministry of Agriculture 2019). In addition, BR results led the ministry to review its national data collection surveys and protocols, resulting in the incorporation of several BR indicators into national surveys to ensure that they are regularly tracked (Togo, Ministry of Agriculture 2019).

\section{Mutual Accountability: Empirical Evidence}

This section explores whether mutual accountability processes are associated with expected Malabo outcomes such as increased agricultural productivity, and whether there is evidence that mutual accountability processes accelerate agricultural transformation. To do so, we estimate a simple model of the following form:

$Y_{i j}=\alpha_{j}+\beta_{j} A g \operatorname{Exp}_{i}+\theta_{j} \operatorname{Land}_{i}+\varepsilon_{i j}$

$X_{i j}=\delta_{j}+\pi_{j} Y_{i j}+\rho_{j} Z_{i j}+\epsilon_{i j}$

$A g \operatorname{Exp}_{i}=\gamma_{0}+\gamma_{1} C A A D P_{i}+\gamma_{2} M A_{i}+\mu_{i}$,

where $Y_{i j}$ represents the level of outcome $j$ ( $j=$ land productivity, labor productivity) for country $i, \operatorname{AgExp} i$ is the level of public agricultural expenditures, $X_{i j}$ is the share of agricultural employment in total employment, $Z_{i j}$ is a set of control variables (population growth and life expectancy), and $C A A D P_{i}$ and $M A_{i}$ capture country $i$ 's commitment to CAADP and mutual accountability processes, respectively. The variables $\varepsilon_{i j}, \epsilon_{i j}$ and $\mu_{i}$ are error terms. This empirical specification explicitly recognizes that the level of agricultural expenditures is endogenous, and it includes the $C A A D P$ and $M A$ variables in the dual roles of explanatory variables and instruments for the level of public agricultural expenditures. The use of these variables as instruments is consistent with the hypothesis that involvement in CAADP or mutual accountability processes does not directly affect expected Malabo outcomes, but does enable processes such as allocation of agricultural expenditure to be more targeted and effective. The overall system of
TABLE 15.1-VARIABLES INCLUDED IN THE ESTIMATION ${ }^{\mathrm{a}}$

\begin{tabular}{|c|c|c|c|}
\hline Variable name & Variable description & Source & Period \\
\hline $\begin{array}{l}\text { MA (mutual } \\
\text { accountability) }\end{array}$ & $\begin{array}{l}\text { Conducted a JSR/JSR-A/JSR-L in } \\
\text { past five years }(Y e s=1 ; N o=0)\end{array}$ & ReSAKSS (2020) & $2008-2018$ \\
\hline $\begin{array}{l}\text { Population growth } \\
\text { rate }\end{array}$ & Population growth (annual \%) & $\begin{array}{l}\text { Word Development } \\
\text { Indicators (World } \\
\text { Bank 2020) }\end{array}$ & 2008-2018 \\
\hline Life expectancy & $\begin{array}{l}\text { Life expectancy at birth, total } \\
\text { (years) }\end{array}$ & $\begin{array}{l}\text { Word Development } \\
\text { Indicators (World } \\
\text { Bank 2020) }\end{array}$ & $2008-2018$ \\
\hline Land & Agricultural land (sq. km) & $\begin{array}{l}\text { Word Development } \\
\text { Indicators (World } \\
\text { Bank 2020) }\end{array}$ & 2008-2018 \\
\hline $\begin{array}{l}\text { Agriculture value } \\
\text { added per worker }\end{array}$ & $\begin{array}{l}\text { Agriculture, forestry, and } \\
\text { fishing, value added per worker } \\
\text { (constant } 2010 \text { USD) }\end{array}$ & $\begin{array}{l}\text { Word Development } \\
\text { Indicators (World } \\
\text { Bank 2020) }\end{array}$ & 2008-2018 \\
\hline $\begin{array}{l}\text { Agriculture value } \\
\text { added per hectare }\end{array}$ & $\begin{array}{l}\text { Agriculture, forestry, and } \\
\text { fishing, value added per hectare } \\
\text { (constant } 2010 \text { USD) }\end{array}$ & $\begin{array}{l}\text { Word Development } \\
\text { Indicators (World } \\
\text { Bank 2020) }\end{array}$ & 2008-2018 \\
\hline CAADP & 1 if participant, 0 otherwise & ReSAKSS (2020) & 2008-2018 \\
\hline $\begin{array}{l}\text { Agriculture } \\
\text { expenditure }\end{array}$ & $\begin{array}{l}\text { Government agriculture } \\
\text { expenditure (constant } 2010 \\
\text { USD, million) }\end{array}$ & ReSAKSS (2020) & $2008-2018$ \\
\hline
\end{tabular}

Source: Authors, based on data from ReSAKSS (2020) and World Bank (2020).

Notes: JSR = joint sector review; JSR-A = JSR assessment; JSR-L = JSR-like process; USD = US dollars.

a Estimation includes 52 African countries. Sahrawi Arab Democratic Republic, Somalia, and South Sudan were excluded because of a sizable number of missing observations.

equations is estimated using three-stage least squares (3SLS). Table 15.1 presents the variables included in the estimation.

For $Y_{i j}$ we use land productivity and labor productivity; these are level 2 Malabo outcomes. This treatment is consistent with the Malabo results framework, which states that level 2 outcomes are realized only once the actions specified as level 1 outcomes are completed; the level 1 outcomes include the accomplishment of those actions specified in the CAADP and mutual accountability processes (AUC and NPCA 2011). To fully capture the effect of mutual

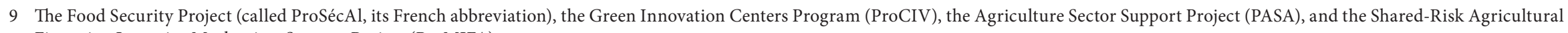
Financing Incentive Mechanism Support Project (ProMIFA). 
accountability on agricultural transformation, we use data collected by ReSAKSS on JSRs as a proxy for mutual accountability. More specifically, we utilize each country's reports on whether it conducted JSRs or JSR-like processes in the past five years. The CAADP indicator covers a country's performance in three areas: CAADP process completion; existence and quality of a multisectorial and multistakeholder coordination body; and CAADP-based policy and institutional review, policy setting, and support.

As discussed in "Mutual Accountability and Agricultural Transformation," above, structural transformation can be defined as the reallocation of production resources across sectors, typically from lowproductivity to high-productivity sectors (Lewis 1954; Herrendorf, Rogerson, and Valentinyi 2014). In Africa, the agriculture sector is a low-productivity sector that utilizes much of the available labor resources (Gollin, Lagakos, and Waugh 2014). McMillan and Harttgen (2014) found that African countries' economies have been growing due to the reallocation of labor from agriculture to manufacturing and services. Moreover, the literature has characterized agricultural transformations as a necessary condition for structural transformations, except in "island" economies such as Hong Kong or Singapore (Timmer 2007). In countries with stronger agricultural mutual accountability processes, does agricultural transformation provide a more robust contribution to structural transformation?
TABLE 15.2-REGRESSION RESULTS (2008-2018)

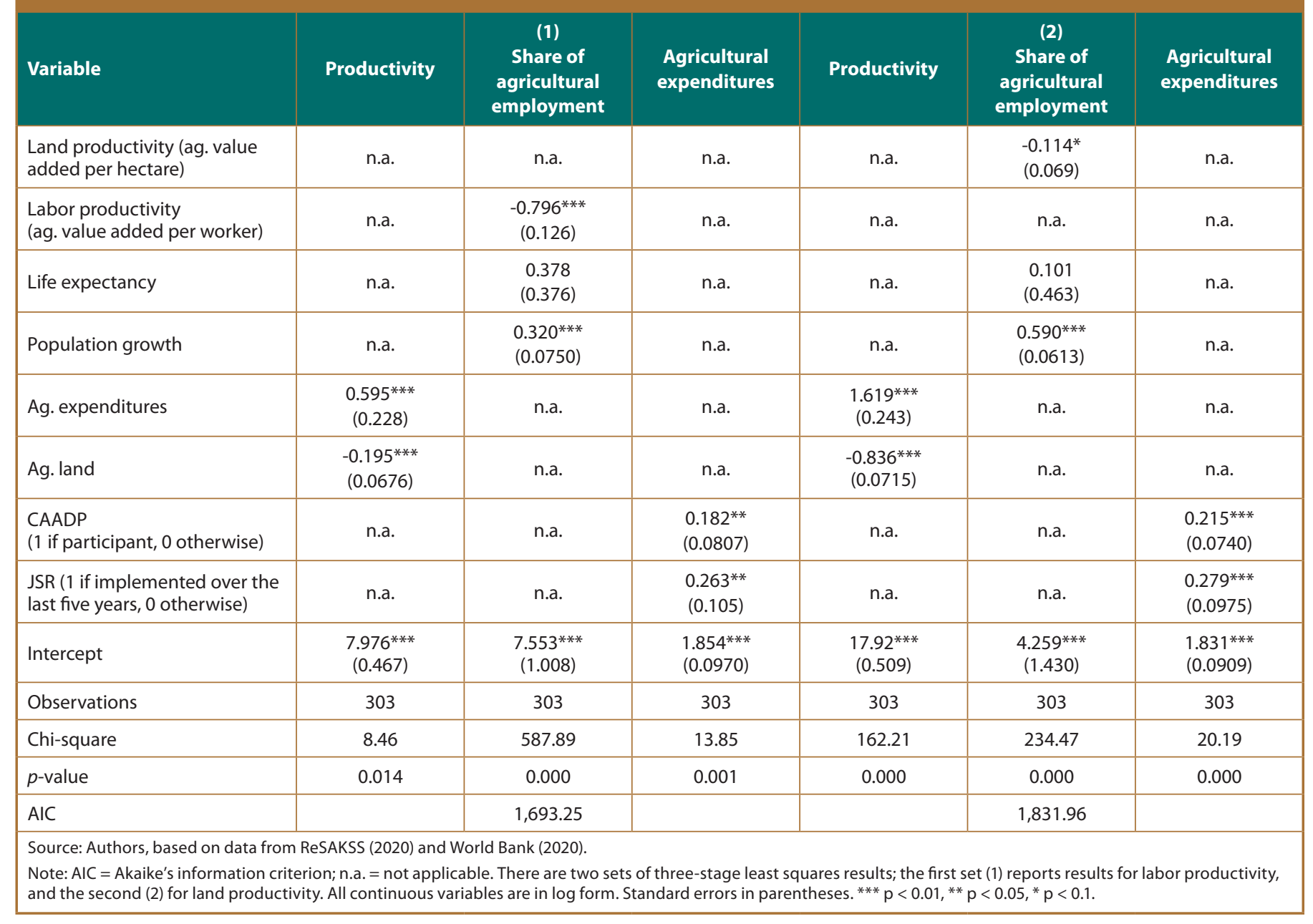

The 3SLS regression results are presented in Table 15.2. In the first stage, our findings confirm the importance of both CAADP participation and mutual accountability in promoting agricultural investments through increases in public expenditures for the agriculture sector. This corroborates the first hypothesis, namely that better agricultural policy systems as exemplified by the CAADP program and mutual accountability process are associated with higher levels of public agricultural expenditure. The results also suggest a positive and significant 
effect of public agricultural expenditures on both labor and land productivity. These results confirm the hypothesis that increased investment in agriculture would spur agricultural growth through productivity gains.

Overall, these results suggest that mutual accountability and the CAADP process are associated with increased agricultural spending. As pointed out by Benin (2018), agricultural expenditures may increase with participation in CAADP because, in general, the CAADP process strengthens the much-needed political will to invest; creates peer pressure within the sector and among countries, which then leads to investment; and more important, by responding to citizens' demands for inclusiveness as well as accountability, also encourages investments.

Our findings also confirm the existence of agricultural and structural transformation because an increase in agricultural productivity (of both labor and land) leads to a decline in the share of agricultural employment in total employment. The elasticities of agricultural employment with respect to productivity are negative and significant. The overall implication is that mutual accountability creates an incentive to increase investment in agriculture, which is likely to increase land and labor productivity. If sustained, the increase in agricultural productivity will trigger an exit of labor from the agriculture sector, leading to a significant reduction in the share of agriculture in overall employment. Ultimately, countries engaged in mutual accountability processes are likely to experience faster agricultural transformation.

\section{Concluding Remarks}

As a multistakeholder mechanism, mutual accountability creates a platform whereby commitments around common development goals can be efficiently executed and monitored. In the context of inefficient markets and weak contracting mechanisms, such as those pervasive in Africa, mutual accountability offers credible incentives through reputational forces and peer pressure to ensure fulfillment of commitments to achieve a common vision and effect behavioral change. This chapter has presented both the theoretical underpinnings of mutual accountability and its application in the context of agricultural transformation in Africa. It has also conducted a comprehensive analysis of JSRs and the BR, including a quantitative assessment of mutual accountability's contribution to agricultural transformation in Africa.
Under the CAADP/Malabo agenda, mutual accountability is based on shared interests and values, as well as commitments to achieve common goals, without any specific political, legal, or economic sanctions. Its enforceability relies on social or reputational forces such as peer pressure or peer review. Indeed, the BR process is already showing that reputational forces can be effective in getting $\mathrm{AU}$ member states to voluntarily participate in reporting progress toward the common CAADP/Malabo agenda. A total of 49 out of $55 \mathrm{AU}$ member states submitted reports for the $2019 \mathrm{BR}$, compared with 47 out of 55 in 2017, and the best-performing countries were honored among their peers, a practice that can help incentivize other countries to take measures to improve their own agricultural transformation outcomes.

A growing body of evidence shows that mutual accountability contributes to agricultural transformation through improvements in agriculture sector governance, policy efficiency, improved strategies, and policy and institutional reforms. Information collected from ministries of agriculture in a handful of countries suggests that the 2017 and 2019 BRs have led to policy changes and adjustments that are likely to boost agricultural transformation processes in the countries. Regression analysis shows that mutual accountability is associated with greater public agricultural expenditures, which in turn increase agricultural productivity. Our findings also confirm the existence of structural change in the agriculture sector, with an increase in labor productivity (measured as agricultural value added per worker) leading to a decline in the share of agricultural employment in total employment. The findings further suggest that countries implementing the CAADP's mutual accountability processes are experiencing a faster track toward structural change.

To accelerate the pace of agricultural transformation in Africa, it is essential that African countries maintain their commitment to the CAADP/Malabo agenda as well as its related mutual accountability processes. Doing so will require governments to demonstrate leadership of an inclusive process, from developing a shared agenda to monitoring and reviewing commitments to having inclusive dialogue around the commitments. Moreover, soft incentives associated with reputational, relational, and peer pressure are important for ensuring accountability and the enforceability of commitments. There is also a need to build the capacities of governments and NSAs to generate shared agendas, monitor and review progress, and engage in dialogue and debate. Finally, JSRs and the BRs have highlighted the urgent need to improve data quality and 
strengthen country capacities for data collection, M\&E, and analysis-all central to ensuring credible data and information to accurately track progress toward Africa's agricultural transformation.

Amid the COVID-19 pandemic, we have witnessed mutual accountability operating at regional and global scales. Recognizing the negative secondary impacts of border closures, AU and the Food and Agriculture Organization of the United Nations issued a joint declaration and commitment on "...supporting access to food and nutrition for Africa's most vulnerable; providing Africans with social protection; minimizing disruptions to the safe movement and transport of essential people, and to the transport and marketing of goods and services; and keeping borders open on the continent for the food and agriculture trade" (FAO 2020, 4-6).

Mutual accountability provides a framework for coordinated multistakeholder responses to global issues such as COVID-19 and their country effects. The COVID-19 pandemic has increasingly made it clear how important strong accountability systems are for mitigating the immediate impacts to public health as well as the secondary impacts to food and water systems, local resilience, and the economy. Coordinated policy systems, responses, and accountability across countries, governments, the private sector, and civil society within countries are essential to minimize the impacts of COVID-19. 